\title{
DEFENSE MECHANISMS OF ARTHROPODS. II. THE CHEMICAL AND MECHANICAL WEAPONS OF AN EARWIG. ${ }^{1}$
}

\author{
By T. EISNER \\ Department of Entomology, Cornell University, \\ Ithaca, N. Y.
}

The European earwig, Forficula auricularia Linn., possesses two pairs of small sac-like glands (Vosseler, I890) situated dorsally in the abdomen, and opening on the posterior margins of the third and fourth abdominal tergites (text fig. I). The principal active components of their secretion have recently been identified as 2-methyl, and 2-ethyl-p-benzoquinone (Schildknecht and Weis, 1960). 'The glands have always been suspected to serve in defense against predators, and this suggestion, although advanced originally in lack of evidence, appears recently to have received at least indirect support, since it is now known that the quinone-containing secretion of certain other insects are, in fact, extraordinarily effective repellents (Eisner 1958a, I958b).

In addition to the glands, Forficula possesses the typical dermapteran pincers, and these too have been claimed to play a defensive role (in addition to other roles, including prey capture), although the evidence is here again circumstantial at best (Burr, I910; Gadeau de Kerville, I905; Rau, I933).

The purpose of this note is to present the results of some experiments designed to test whether the glands and pincers are really the effective defensive devices they were presumed to be. ${ }^{2}$

\section{The Pincers}

In order to facilitate close-range observation of the earwigs, they were attached to rods (by a technique used previously and already described in detail: Eisner 1958a, I958b; Eisner et al., 1959), and adjusted to a normal stance on the substrate as shown in Plate 7 , figure I. In this way they were prevented from scurrying about, while at the same time retaining full mobility of head, abdomen, and legs.

By subjecting such animals to mild traumatic stimuli, applied locally to the body or to individual appendages by pinching with fine forceps or touching with a warm needle, it was possible to witncss very clearly the way in which the pincers are put to a defensive use.

\footnotetext{
${ }^{1}$ This study was supported by Grant E-2908 of the U.S. Public Health Service.

${ }^{2}$ Forficula auricularia is established in the U.S.A. The specimens used were taken in Lexington, Mass.
} 
No sooner had a stimulus been applied than the animals responded by revolving their abdomen, bringing the pincers to bear upon the region traumatized. They usually succeeded in grasping the instrument used for stimulation (Plate 7, figs. 2, 3) and, by pulling and tugging, attempted to free themselves from it. They sometimes released their grip momentarily, but as a rule persisted tenaciously for as long as the stimulus was maintained. The abdomen is remarkably maneuverable, being capable of bending and twisting to such an

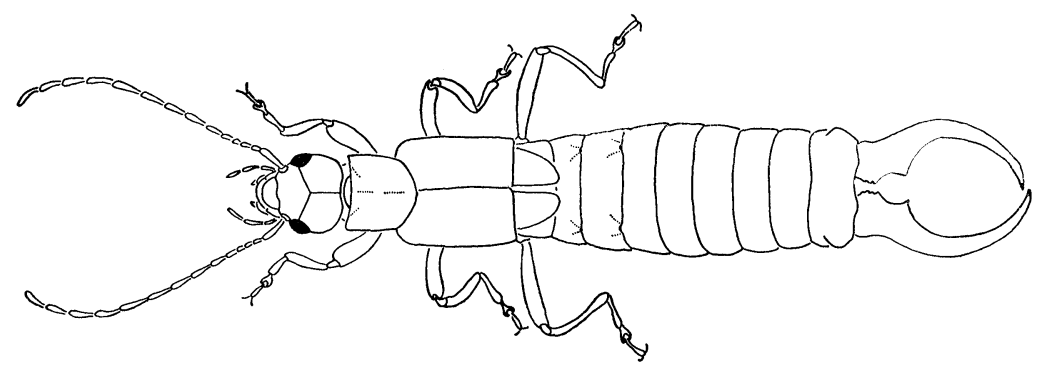

Text Figure 1. Forficula auricularia Linn. showing the four glandular openings and the cuticular sculpturing around them on the third and fourth abdominal tergites.

extent that virtually no body part other than the abdomen itself is inaccessible to the pincers. Since the abdomen responds rapidly and with precision, the pincers can be shifted accurately and without delay from one region to another. This became quite clear when the animals were subjected to a rapid sequence of stimuli applied to different parts of their body.

The pressure that the animals can exert with the pincers is considerable. From personal experience, I can attest to the claim (cited by Burr, I9IO) that the sharp prongs can pierce human skin (the prongs of the male are larger and somewhat more effective than those of the female).

\section{The Glands}

Adult earwigs, affixed to rods as before, were again subjected to localized stimulation, but this time they were placed on sheets of filter paper impregnated with an acidulated KI-starch solution. This paper discolors to an intense blue-black in the presence of quinones, and can therefore be used as an appropriate indicator for the detection of glandular discharges.

In Plate 8 are shown the types of pattern produced by the secretion. Evidently, the gland contents do not merely ooze out, - as 
they do in certain millipedes and tenebrionid beetles that also discharge quinones (Eisner, I96I) - but rather are ejected forcibly as a spray. It is also apparent from the figures that the spray is not ejected in a fixed direction, but is actually aimed with considerable precision toward the particular region of the body subjected to stimulation. This finding, although new for earwigs, is by no means novel as it applies to arthropods in general: bombardier beetles, certain cockroaches, whipscorpions, and a variety of others, are all known to aim their spray (Eisner, 1958a, 1958b, 196r; Eisner et al., I959; Eisner et al., I96I).

The mechanism by which the earwigs aim is intimately linked with the defensive use of their pincers, since by revolving the abdomen at its base while bringing the pincers toward the stimulus, the gland openings are automatically pointed in the proper direction. It is interesting in this context that the forceps seem to be used in precedence to the glands. When a stimulus is applied, a secretory discharge usually does not follow at once. As a rule, the pincers are brought into action first, and then, only after their persistent use for several seconds has proven futile, is the spray finally ejected. When the stimulus applied is a more violent one, however, such as when the head or abdomen is pinched with hot broad-tipped forceps, or the animal simply seized between the fingers, the discharge may follow with little or no delay. In other arthropods with similar defensive glands, but lacking such auxiliary mechanical devices as the earwig's pincers, even a slight traumatic disturbance usually elicits a prompt discharge (Eisner 1958a, I958b; Eisner et al., 1959; Eisner et al., I96I).

Up to six consecutive discharges could be evoked from a single earwig, but usually they produced no more than four. The amount of secretion ejected decreases progressively, until finally there are produced on the paper no more than a few spots at close range.

The earliest that an earwig with depleted glands was ever tested to check on the restoration of its secretory supply was after a period of five days: by this time it was again able to discharge three times.

Explanation of Plate 7

Figure 1. Earwig fastened to hook, in normal stance.

Figure 2. Earwig having its right metathoracic leg pinched with forceps, responding by bringing its pincers to bear upon the forceps.

Figure 3. Same as preceding, but the stimulus is applied to the right antenna. 

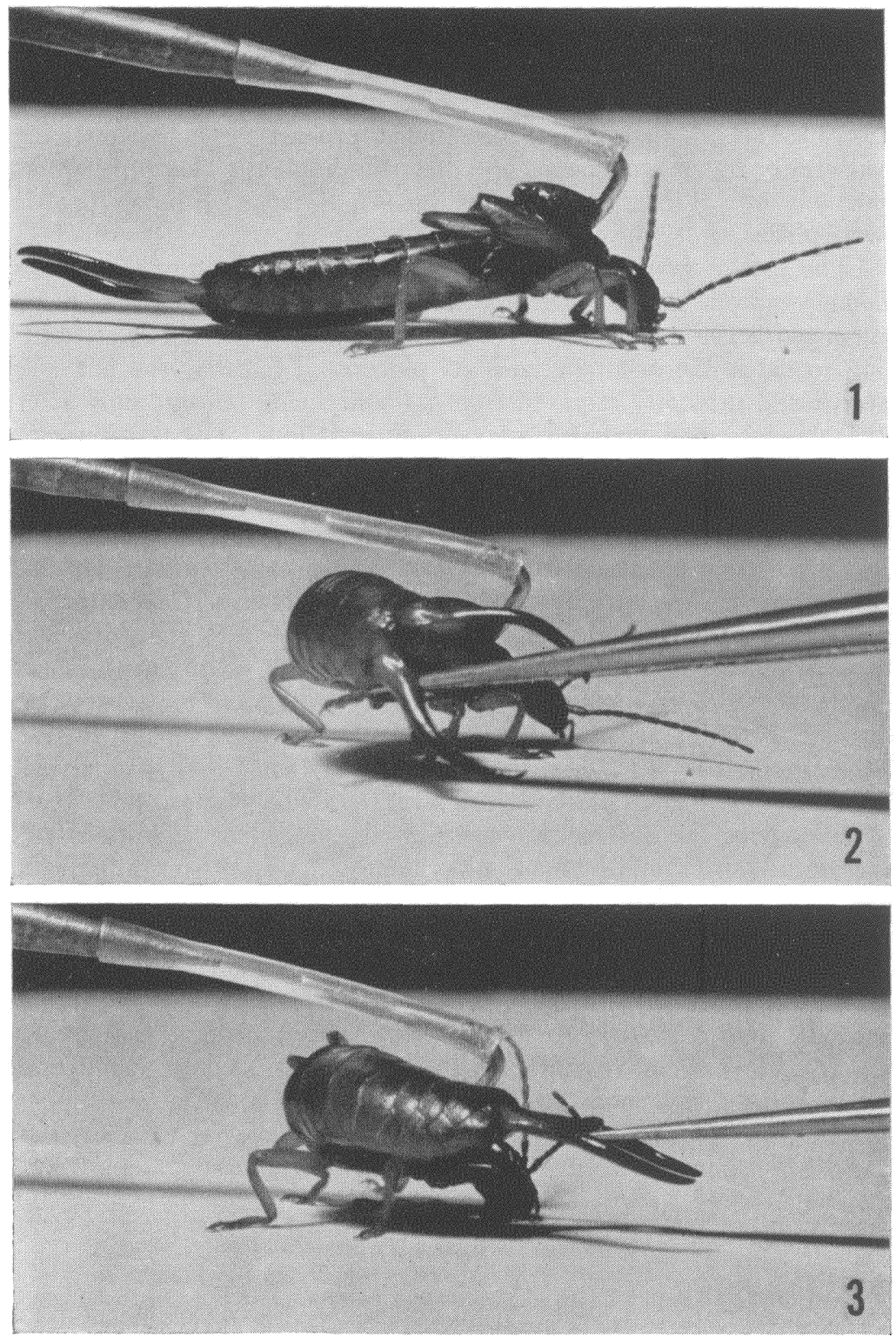

EISNer - Defense Mechanisms 


\section{Encounters with Predators}

ANTs [Pogonomyrmex badius (Latreille)]

The experiments were carried out under the same conditions as prevailed in previous comparable studies (Eisner I958a, I958b), the earwigs being affixed to rods and placed individually close to the nest entrance of a laboratory colony of the ant. Sheets of KI-starch paper were placed under the earwigs.

The ants at first attacked singly or in groups of two or three. No sooner had one of them grasped the earwig with its mandibles (often mere contact seemed to suffice), than the earwig responded by attempting to catch the assailant with its pincers. Typically, the ant was seized and promptly removed from its hold, being released only after the abdomen had uncoiled and straightened out. The uncoiling of the abdomen is a rapid spring-like action, with the result that the ant is sometimes flipped several centimeters away.

No discharges were produced during these first attacks, all ants being successfully fought off by the use of the pincers alone. Gradually, however, the activity of the ants around the nest entrance became considerably intensified (perhaps in response to the release of the ant's own alarm substance; see Wilson, I958), and within minutes the earwig was surrounded by a swarm of workers, some attempting to bite and sting it, others merely scurrying over its body. It was then that a discharge was finally produced. The result was an instantaneous dispersal of the entire swarm. For a few seconds thereafter none of the ants ventured within the immediate vicinity of the earwig. Many showed typical grooming activities, others underwent the conspicuous dragging behavior already noticed in this ant and the related $P$. occidentalis (Cresson) under similar circumstances involving insects which spray (Eisner I958a, I958b; Eisner et al., I96I). The swarm soon closed in again, but for yet another several seconds there occurred no real attacks, the ants turning and fleeing the moment they made contact with the earwig. That this avoidance behavior may have been attributable to residual secretion remaining on the earwig's body was suggested by the fact that a small strip of indicator paper held within millimeters from the earwig rapidly became discolored.

Explanation of Plate 8

Figures 1, 2, 3. Three different discharges elicited by pinching respectively the end of the abdomen (figure 1), the right mesothoracic leg (figure 2), and an antenna (figure 3 ). (The pictures were taken shortly after discharge, and the abdomens were therefore no longer in the exact positions they had assumed at the time of spraying). 

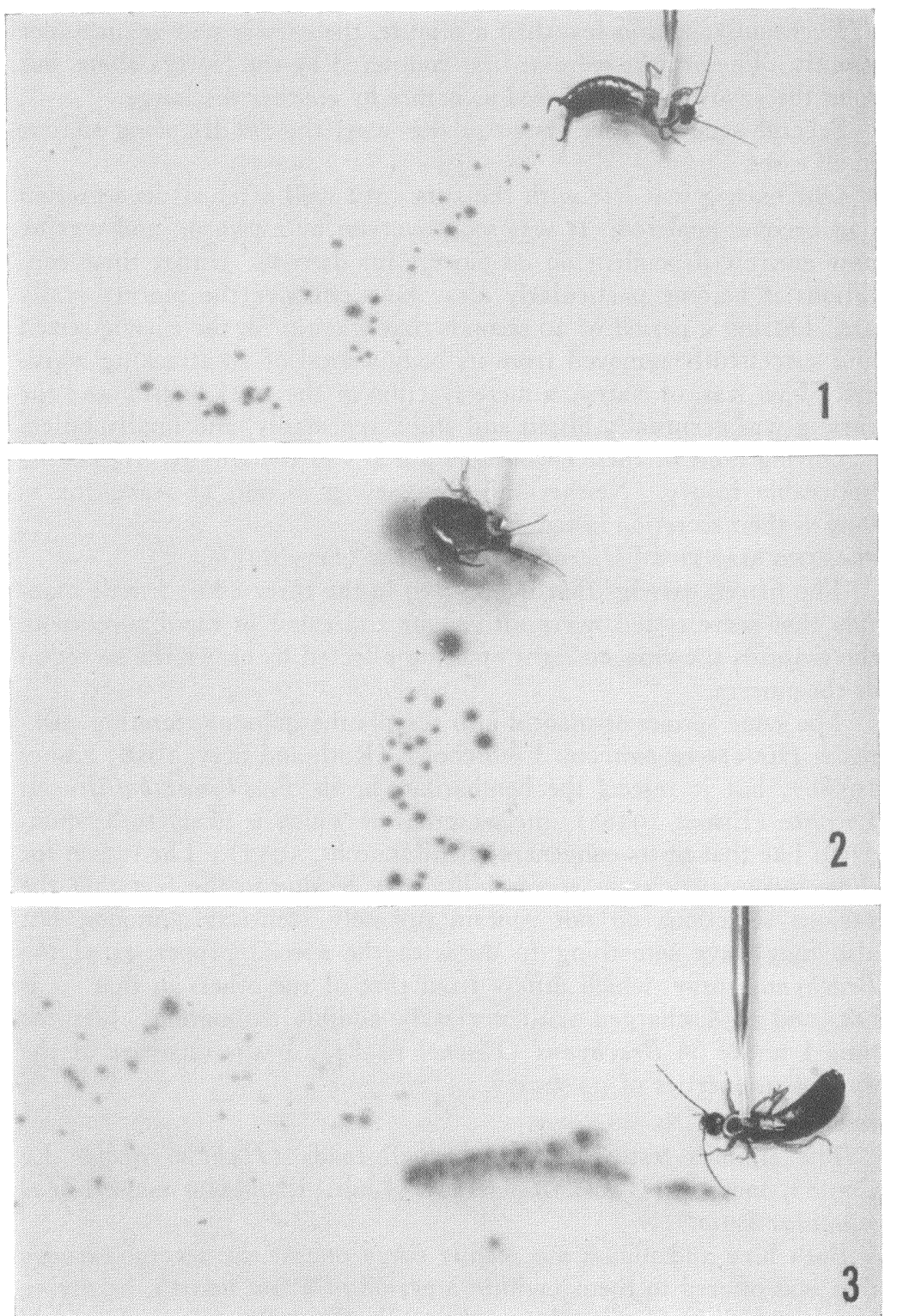

Eisner - Defense Mechanisms 
Eventually, within less than a minute, the earwig was again under assault. The attacks were at first countered by the pincers alone, but soon the swarm was dispersed as before by another discharge.

Several earwigs were tested in this way, the results being similar in all cases.

One earwig was left with the ants until well after all its secretion had become depleted. It was soon overrun by a swarm, and was by now entirely dependent on its pincers for defense. Under these conditions it became particularly clear how effective the pincers really are. During a period of 20 seconds that was timed, the earwig seized and successfully removed from its body a total of I9 attacking workers. This was, of course, a mere fraction of the total swarm, and the earwig was eventually bitten and stung repeatedly, and finally killed.

During none of these encounters did any of the ants receive lasting noticeable injury. Neither did the earwigs - not, at least, for as long as their secretion lasted.

PRAYING MANTIDS [Hierodula patellifera (Serville)]

The fifteen earwigs that were given to the three adult female mantids that were tested, were all caught and eaten in rapid succession, the mantids showing no signs of being affected by either the secretion or the pincers.

The same species of mantid also accepts the quinone-secreting cockroach Diploptera punctata Eschscholtz (Roth and Stay, I958; Eisner I958b), but it rejects the bombardier beetle Brachynus ballistarius Leconte (Eisner 1958a), the secretion of which is likely to be quinonoid like that of its congeners (Schildknecht, I957). The reason for these inconsistencies in acceptability may be due to the fact that the various secretions do not contain precisely identical quinones, but also may have something to do with the special properties of the Brachynus spray, which differs from that of the others in that it is hot, and is discharged with a clearly audible detonation. [At the time I wrote on Brachynus (Eisner, I958a), I was unaware of the thermal properties of its spray].

VERTEBRATES

The animals tested were two small toads (Hyla versicolor Le Conte), one bird [Cyanocitta cristata (Linn.)], and one mouse (Mus musculus Linn.).

Both bird and mouse ate readily every one of the several earwigs that was offered to them (within a period of a few hours), betraying no abnormalities during the meal, or ill effects thereafter. It would be well to bear in mind, however, that before ruling out the repug- 
natorial effectiveness of an arthropod's secretion against a vertebrate, long-term feeding experiments should be made, to test for any discriminatory tendencies that might eventually develop after a greater number of encounters, and particularly in situations where the predator is also given palatable insects as an alternative choice.

With Hyla the results were different. Five of the eleven earwigs offered (over a period of a few hours) were caught and swallowed, but the rest were promptly spat out (there was no apparent order in the sequence in which the earwigs were either taken or rejected). Whether rejection was on the basis of the secretion alone, or was also attributable to trauma induced by the pincers, could not be determined. That the secretion may in itself be repellent is suggested by the fact that benzoquinones are strongly irritating when applied topically to an amphibian: a mere sprinkling of a few crystals of $p$-benzoquinone on $H y l a$ invariably elicits a prompt scratch reflex. The pincers may also be of importance, however. In one instance a frog had difficulty rejecting an earwig, which was seen to have become firmly clamped to its tongue, and which was not removed until the frog used its forelegs to brush it away.

Acknowledgements: I am indebted to Professor Carrol M. Williams of Harvard University, and also to his family, for having collected the earwigs for me, and to Professor Edward O. Wilson for use of his Pogonomyrmex colonies at Harvard. Thanks are also due Professor Kenneth D. Roeder, Tufts University, who made the mantids available at his laboratory, and Dr. J. A. G. Rehn who identified them. Dr. Hermann Schildknecht, University of Erlangen, Germany, was kind enough to let me see his manuscript (Schildknecht and Weis, I960) before its appearance in print.

\section{References Cited}

Burr, M., 1910, Dermaptera. In: The Fauna of British India. Taylor and Francis, London.

EISNER, T., 1958a, The protective role of the spray mechanism of the bombardier beetle, Brachynus ballistarius Lec. J. ins. Physiol. 2: 215-220.

Science 128: 148-149.

1958b, Spray mechanism of the cockroach Diploptera punctata. 1961, The effectiveness of arthropod defensive secretions. Proc. XIth Int. Congr. Entom. (in press).

Eisner, T., F. A. McKittrick, and R. PAYne, 1959, Defense sprays of roaches. Pest Control 27:11-12, 44-45.

Eisner, T., J. Meinwald, A. Monro, and R. Ghent, 1961, Defense mechanisms of arthropods. I. The composition and function of the spray of the whipscorpion, Mastigoproctus giganteus (Lucas) (Arachnida: Pedipalpida). J. ins. Physiol. (in press) 
Gadeau De Kerville, H., 1905, Note sur les functions de la pince des insectes Orthoptères de la famille des Forficulidés. Bull. Soc. Zool. France 30:5363.

RaU, P., 1933, The Jungle Bees and Wasps of Barro Colorado Island. Von Hoffman Press, St. Louis, Mo.

Roth, L. M., and B. STAY, 1958, The occurrence of para-quinones in some arthropods, with emphasis on the quinone-secreting tracheal glands of Diploptera punctata (Blattaria). J. ins. Physiol. 1: 305-318.

Schildknecht, H., 1957, Zur Chemie des Bombardierkäfers. Angew. Chem. 69: $62-63$.

Schildknecht, H., and K. H. Weis, 1960, VI. Mitteilung über Insektenabwehrstoffe. Zur Kenntnis des Pygidialdruisensekretes vom gemeinen Ohrwurm, Forficula auricularia. Zeitschr. f. Naturforsch. 15: 755-757.

Vosseler, J., 1890, Die Stinkdrüsen der Forficuliden. Arch. mikr. Anat. 36: $565-578$

WiLson, E. O., 1958, A chemical releaser of alarm and digging behavior in the ant Pogonomyrmex badius (Latreille). Psyche 65:41-51. 

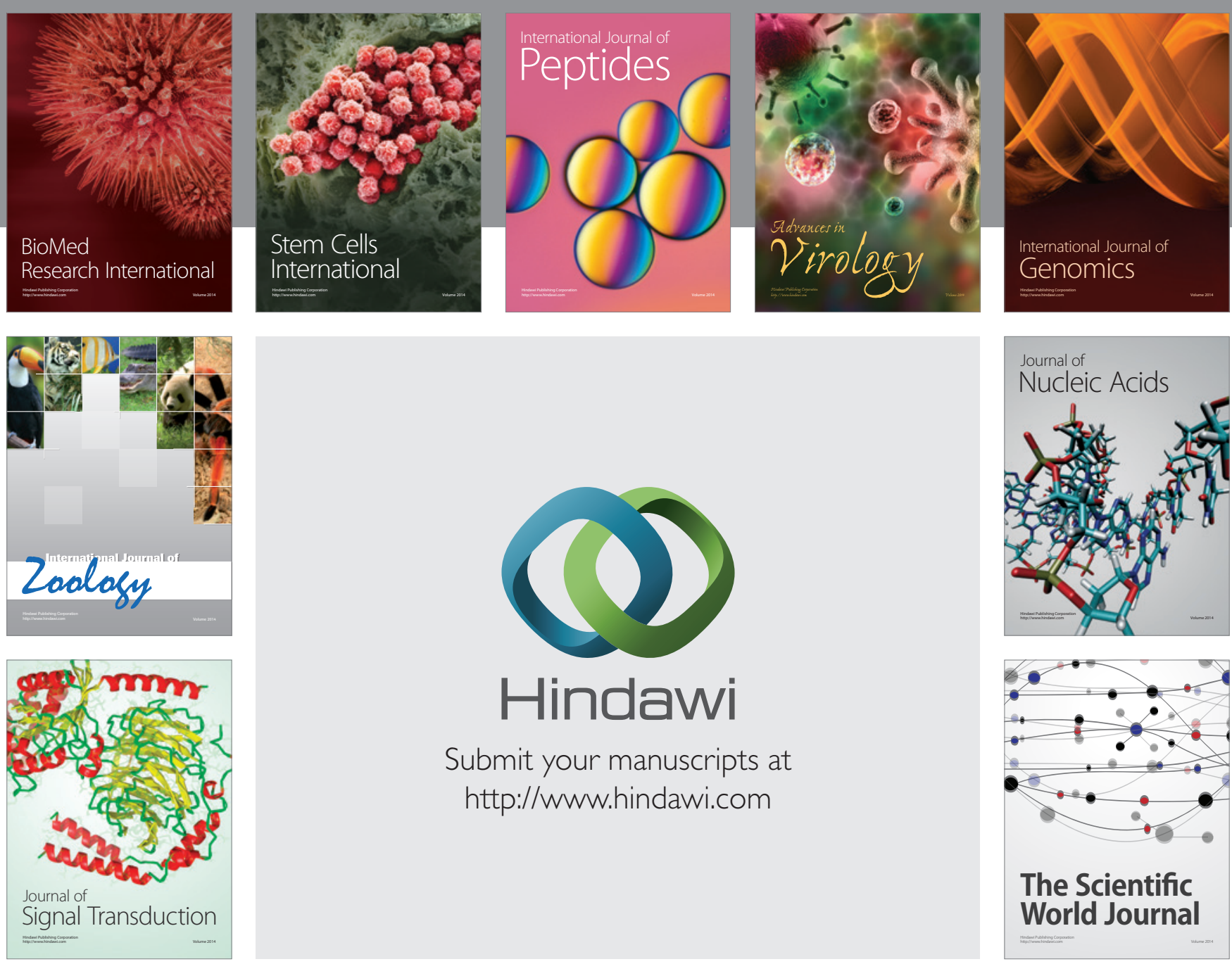

Submit your manuscripts at

http://www.hindawi.com
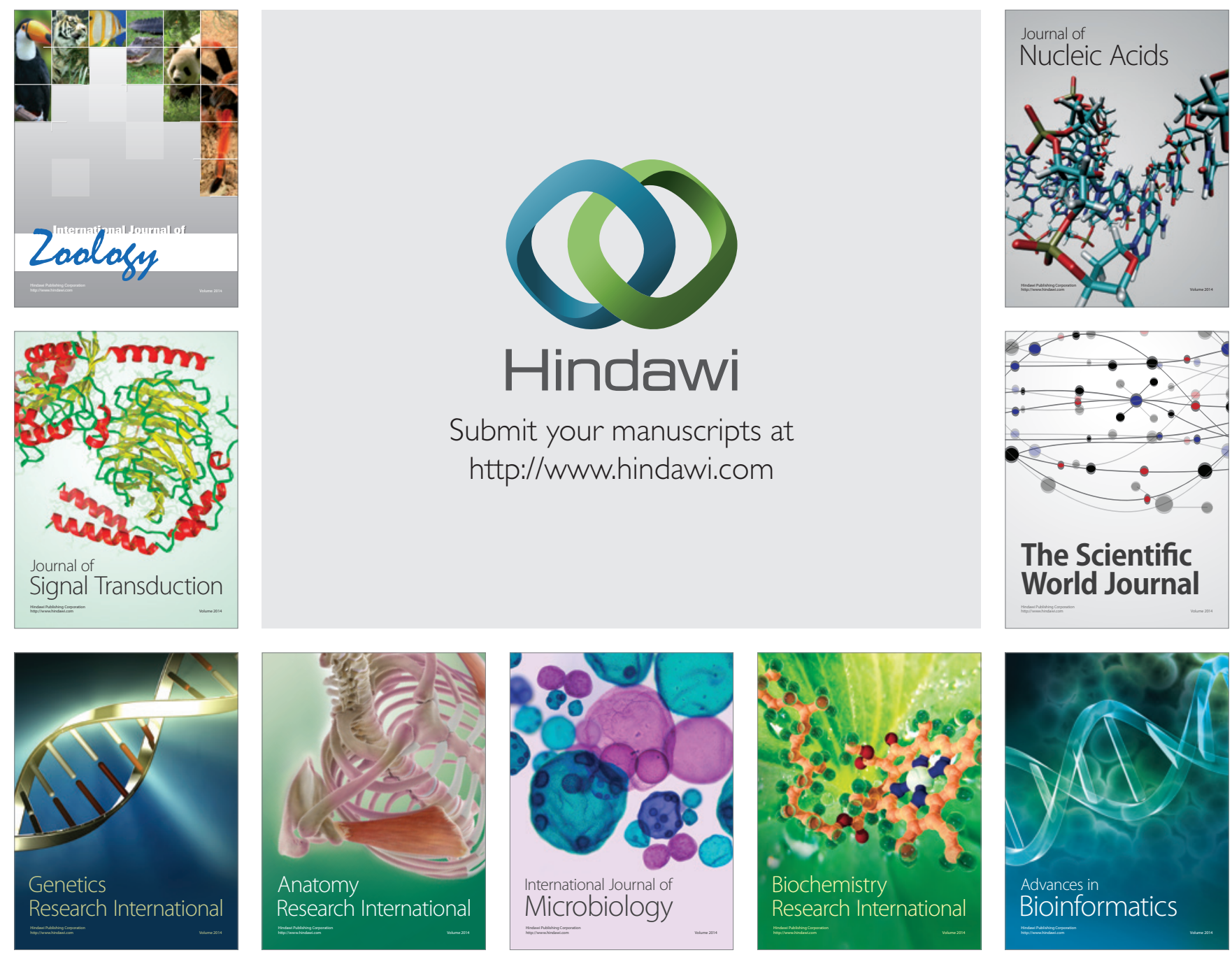

The Scientific World Journal
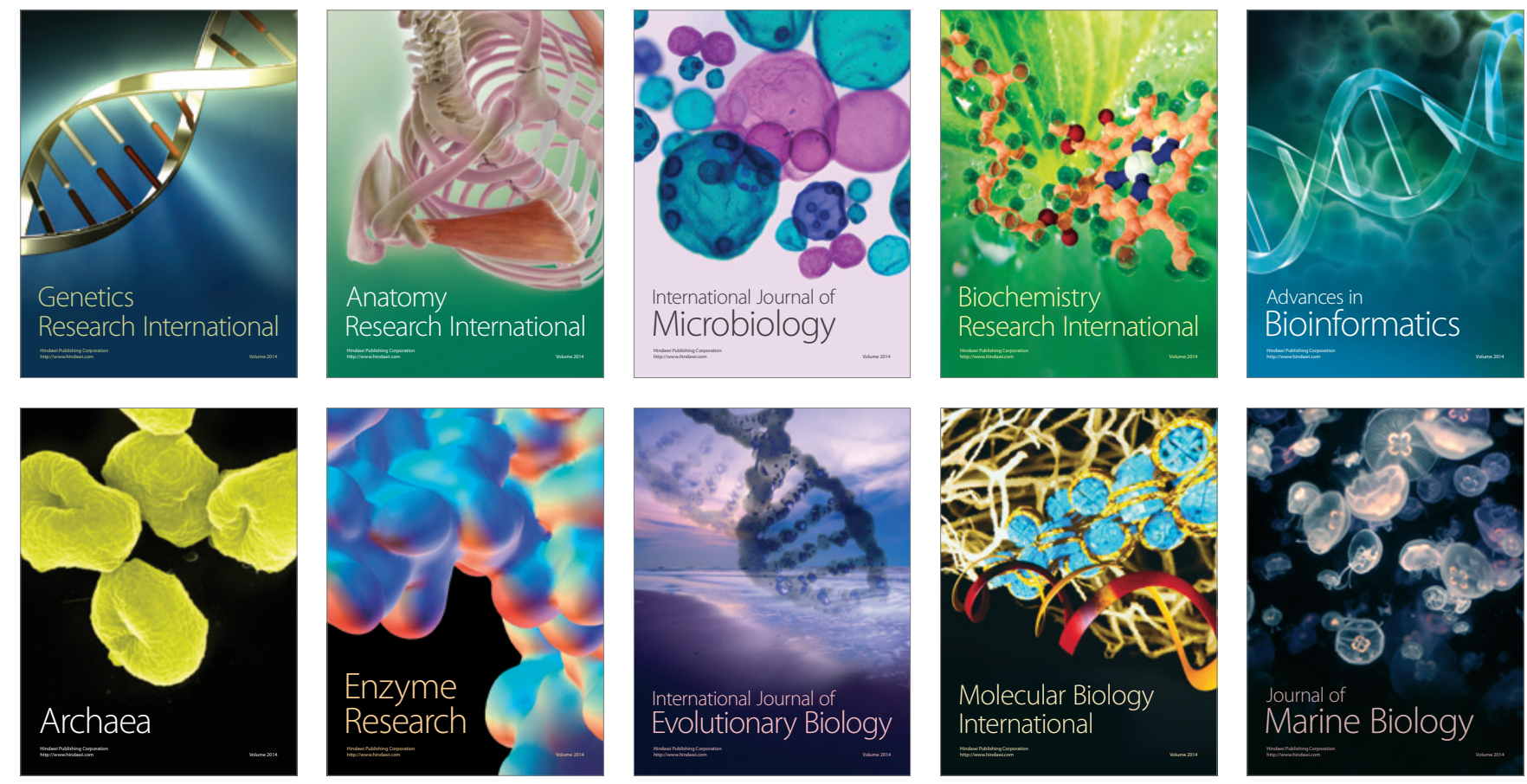